Article

\title{
Survey of Damage Investigation of Babbitted Industrial Bearings
}

\section{Lyle A. Branagan}

Pioneer Motor Bearing Company, 129 Battleground Road, Kings Mountain, NC 28086, USA; E-Mail: 1yleb@pioneer1.com; Tel.: +1-704-937-7000 (ext. 118); Fax: +1-704-937-9429

Academic Editors: Romeo P. Glovnea and Michel Fillon

Received: 28 October 2014 / Accepted: 9 March 2015 / Published: 1 April 2015

\begin{abstract}
This survey collects the efforts to understand the sources and consequences of damage to babbitted industrial bearings, which operate by means of a hydrodynamic, or hydrostatic, film. Major individual damage types are discussed in the context of major damage categories.
\end{abstract}

Keywords: whitemetal; babbitt; journal; thrust; damage

\section{Introduction}

Hydrodynamic bearings support a rotating shaft with its associated loads, by means of a pressure field developed within a lubricant which separates the solid surfaces. Generation of the separating pressure requires the presence of a converging film thickness and lubricant viscosity. With sufficient pressure over a bearing area, complete support of the loads is achieved avoiding contact between the rotating and stationary components. In theory, this hydrodynamic film prevents wear and degradation of the rotating and stationary components.

For industrial equipment, the rotating shaft is more valuable than the supporting bearings. Therefore, the bearing inner diameter is lined with a sacrificial material to absorb damage and to protect the journal surface (for radial bearings) or thrust collar (for thrust bearings) from damage. To serve as a sacrificial material, this lining should be softer than the journal surface and accept contact from hard contaminants in the lubricant.

As a consequence of this material combination, inspection of the lining surface, often a tin-based babbitt (whitemetal) [1], can provide understanding as to both the future operating integrity of the hydrodynamic film, as well as suggesting mechanisms in the machine, lubrication system or bearing which may be degrading. 
This paper outlines the observations relevant to a tin-based babbitt (whitemetal) used for a hydrodynamic bearing and then discusses a wide range of associated degradation mechanisms. Similar discussions and lists of degradation mechanisms have been discussed by other authors over a range of perspectives, as presented in references [2-11].

Some authors have addressed the behavior of tin-based babbitt and other lining materials with partial or boundary lubrication [12,13], but without a hydrodynamic, separating film. While observing the results of partial or boundary lubrication, this paper does not consider the impact of material selection.

\section{Off-Line Observations}

The focus of this paper is on the visual review of the condition of the babbitt (whitemetal) surface after disassembly of the bearing. As the babbitt is softer than the journal (thrust collar) material, damage should be most severe on the babbitt surface.

Two questions can be addressed by the visual observations in conjunction with a review of previous on-line measurements. The first question is whether the bearing is suitable for continuing operation as-is, perhaps after a simple cleaning. The answer to this question depends on whether the condition of the bearing is sufficient to allow successful operation of the hydrodynamic film under expected loads, static and dynamic, as well as avoiding damage during the required startups and shutdowns. The visual observations of the damaged bearing, discussed in this paper, provide the basis for calculating the loss of load capacity. Separately, the design load capacity for the bearing in a particular application would have to be determined. These two considerations allow the determination of suitability for reuse to be determined based on the remaining (degraded) load capacity.

Second, the visual observations and on-line measurements reveal the interaction of the bearing with the machine, lubricant and operating conditions. Most of the mechanisms which degrade the hydrodynamic film will be due to machine or lubricant conditions. Some additional damage mechanisms may represent machine conditions which warrant further investigation, although they have not yet degraded the hydrodynamic film.

\section{Discussion of Bearing Degradation and Damage}

\subsection{Impact on Hydrodynamic Film}

A degraded hydrodynamic film can be defined from several perspectives [14] including:

- Loss of adequate load capacity for normal operation.

- Loss of adequate load margin for anticipated overload.

- Hot operation leading to loss of oil film due to loss of lubricant viscosity.

- Increases in machine vibrations due to bearing wear.

- Increases in machine vibration due to changes in machine dynamics associated with wear of bearing degradation.

Three broad categories of observations can be established: loss of babbitt material, babbitt surface displacement and supporting structure degradation.

Loss of material can be defined in terms of location and volume, with different names and appearance. 
- Scratch-A scratch would have a narrow cross-section but a significant length; the depth of the cross-section can be shallow or deep. Figure 1 shows an axial series of such scratches. A deep scratch would have a depth in excess of 6 times the local minimum film thickness [15], deeper for a longer bearing. The impact of a scratch can be to prevent the development of hydrodynamic pressures over the scratch, degrading the load capacity of the bearing [16], by serving as a leakage path away from a potential load bearing region of the bearing.

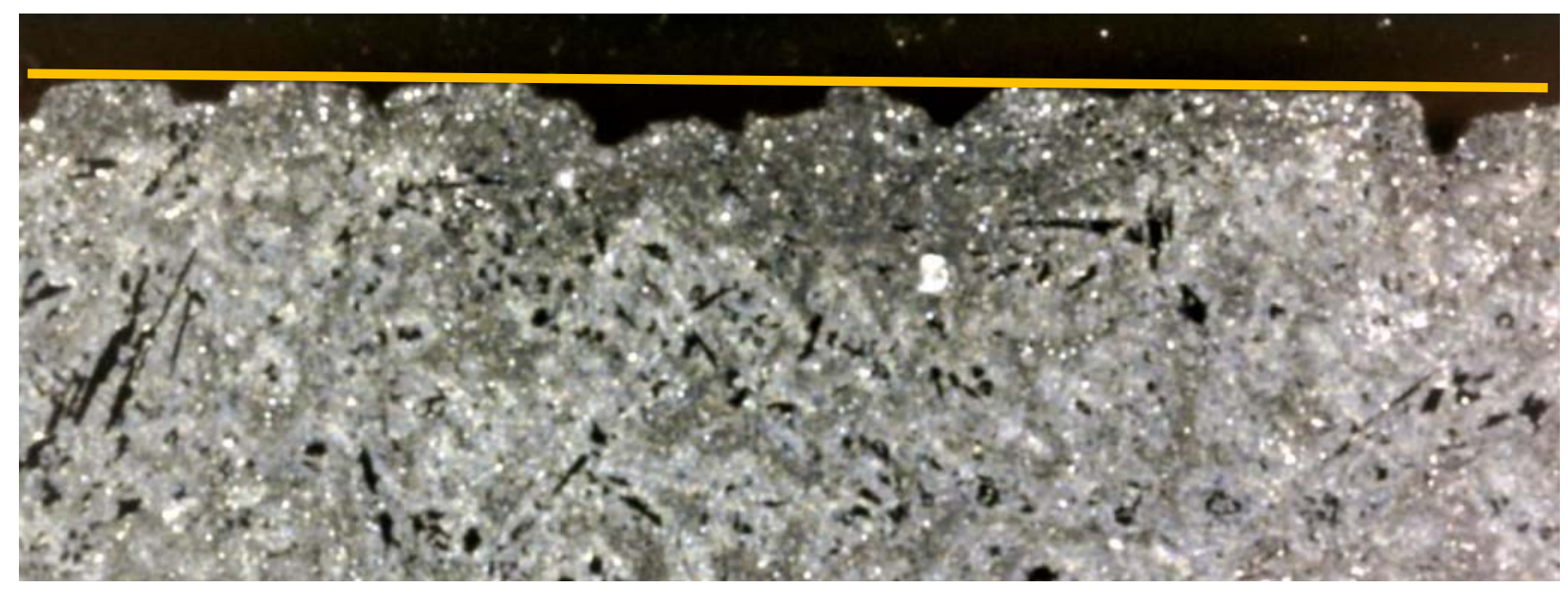

Figure 1. Axial series of scratches at $250 \times$ magnification along a journal bearing with approximate original bore surface indicated.

- Bulk Loss - Bulk loss can be termed a crater, pitting, pothole or cracking depending on the size and form of the damage. Each of these forms represents a deep feature, defined as having a depth in excess 6 times the local minimum film thickness. This depth ratio is based on estimates of the minimum depth necessary for a uniform pressure within the feature. Bulk loss differs from a scratch in that the cross-section is broad rather than narrow. An obvious loss of material, in this case to the full depth of the babbitt, is shown in Figure 2. As listed above, a region of connected cracking is also a form of bulk loss, as it will have the same impact on a hydrodynamic film pressures as a complete loss of material over the same area (Figure 3 ). The impact of material loss is to create a region of uniform hydrodynamic pressure rather than allowing increasing pressure (load capacity) where the film thickness is converging. By contrast, a scratch creates a leakage path for pressurized lubricant from a region of high pressure to low pressure. 


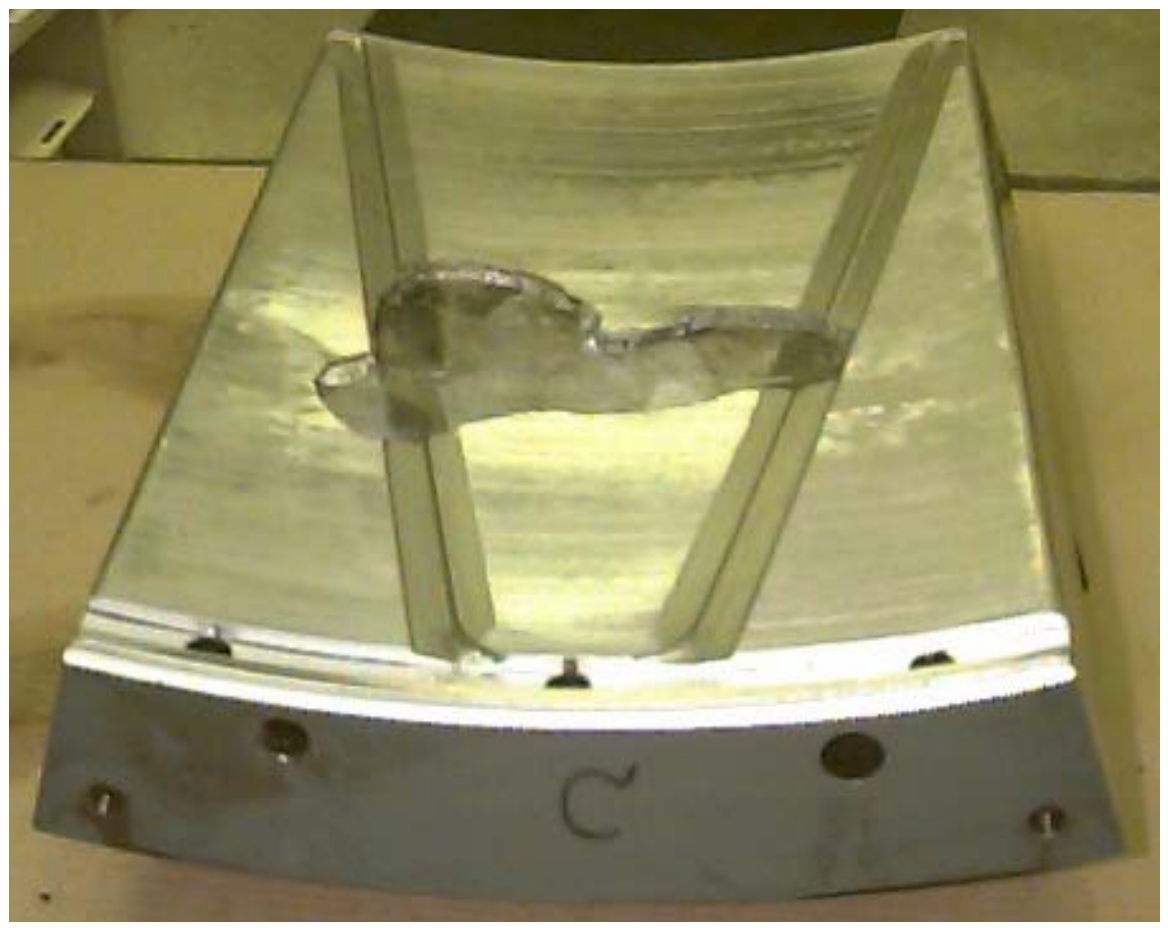

Figure 2. Bulk loss of material in central region of tilting pad radial bearing.

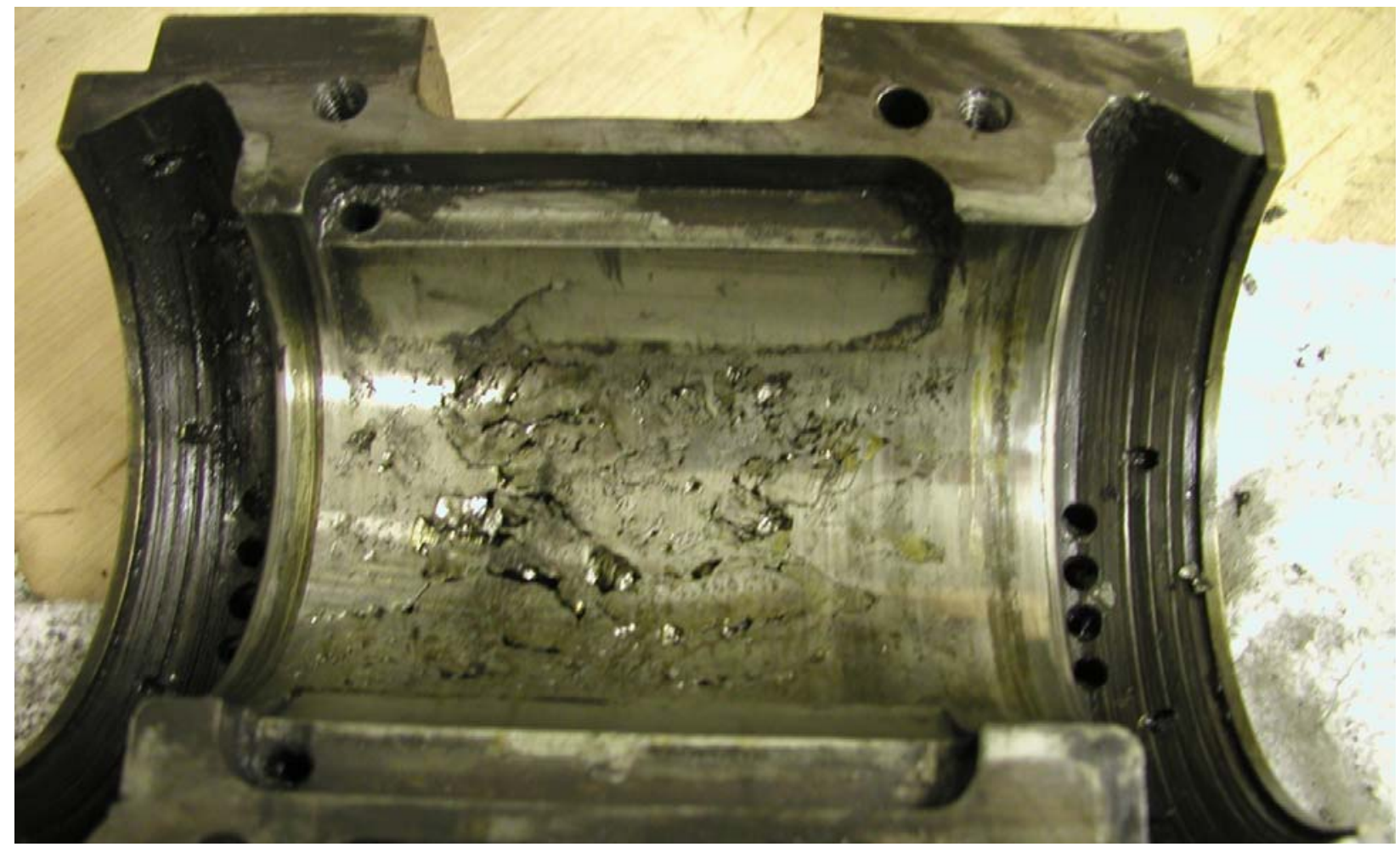

Figure 3. Distributed deep cracking of loaded surface forming an equivalent bulk loss of material.

- Wear-Wear is a loss of material over a wide area with smooth changes in depth (Figure 4). Such wear can occur in spite of bearing operation principally in the hydrodynamic regime ([17-19]), where "zero wear" is theoretically possible. The area may be the full babbitt surface, thus resulting in an increase in clearance, or limited to the loaded region. The impact of wear will depend on the type of bearing under consideration. Many tapered land thrust bearings are 
designed to experience an increase of load capacity due to the increase in land width associated with the wear. On the other hand, the minimum film thickness in a sleeve bearing will decrease with wear. Where adequate supply oil is available, a sleeve bearing may experience a decrease in operating temperature due to wear as a consequence of the increase in circulating flow within the film. With wear a sleeve bearing will experience a decrease in film damping, which may affect the overall machine dynamics.

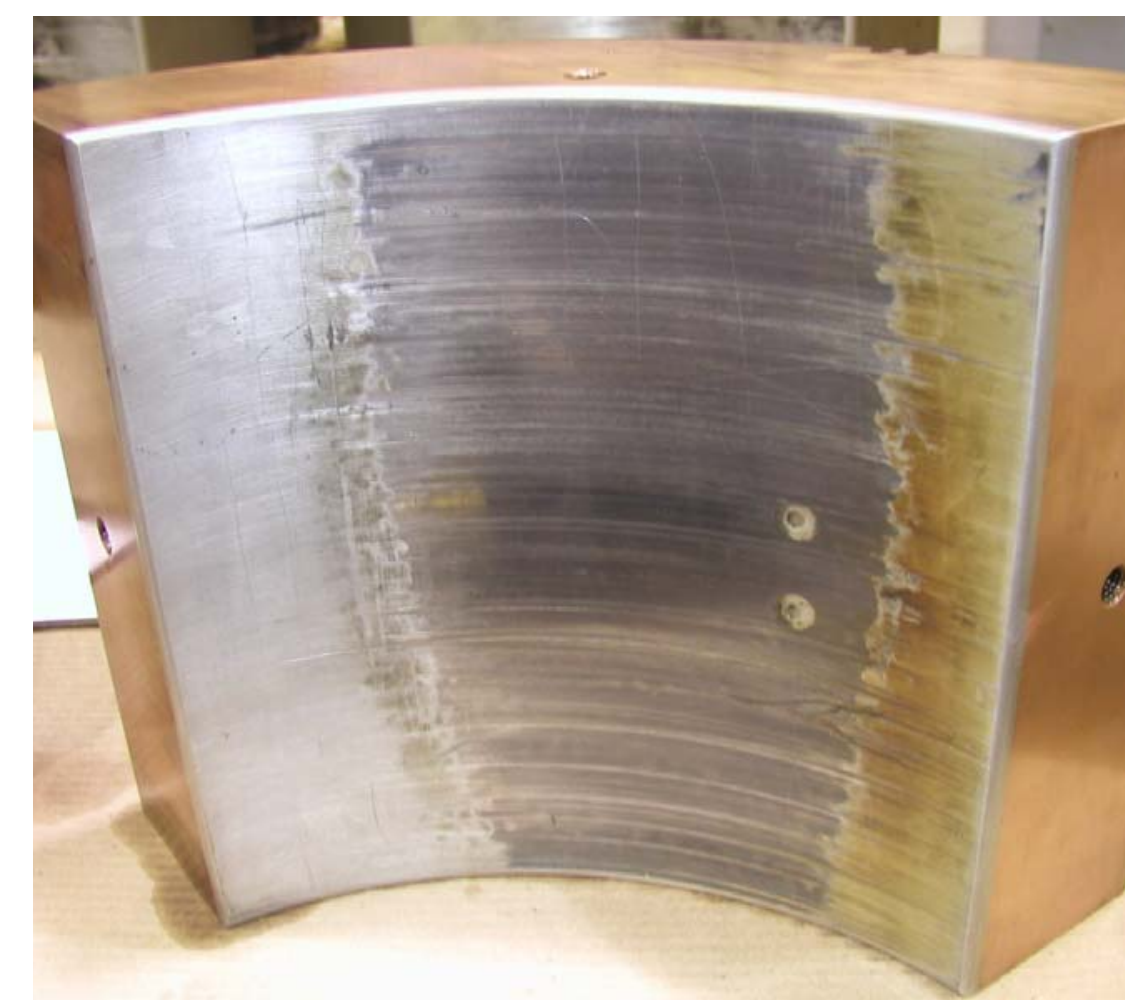

Figure 4. Wide wear pattern (central darkened region) on loaded pad of a gas turbine tilting pad bearing.

In visual appearance a region of multiple scratches would differ from a region of wear. However, the region with multiple scratches of similar depth would have the same impact on the operating hydrodynamic film as wear of that same depth over the region. Multiple scratches could be due to a number of discrete contaminants in the oil or upsets on the journal (thrust collar) while wear could be due to a larger number of finer contaminants.

Surface displacement can be termed creep or wiping.

- Creep would be the surface movement of the babbitt due to a combination of high local pressure and high local temperature which exceeds the local yield strength of the babbitt [20]. Movement of babbitt occurs from the loaded region (high material compressive stress) towards an unloaded region (lower compressive stress) (see region circled in Figure 5). 


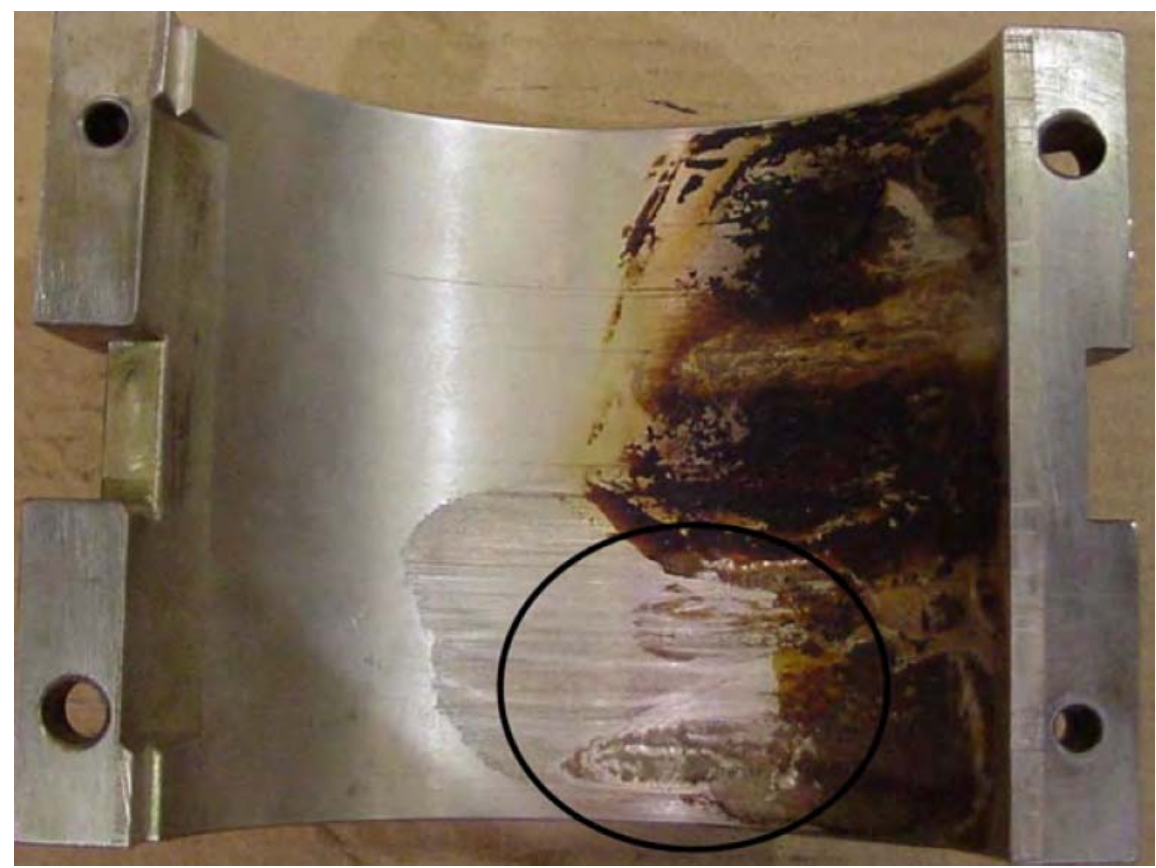

Figure 5. Regions of babbitt material creep in a hot-running region of a cylindrical bearing.

- Occurring more often than creep, wiping represents surface displacement due to contact between the rotating journal (thrust collar) and the babbitt surface (Figure 6). Babbitt may be only slightly displaced or may be moved and deposited to a different region of the bearing (Figure 7). Movement of the babbitt occurs from the region of contact (minimum film thickness) towards a region of larger film thickness.

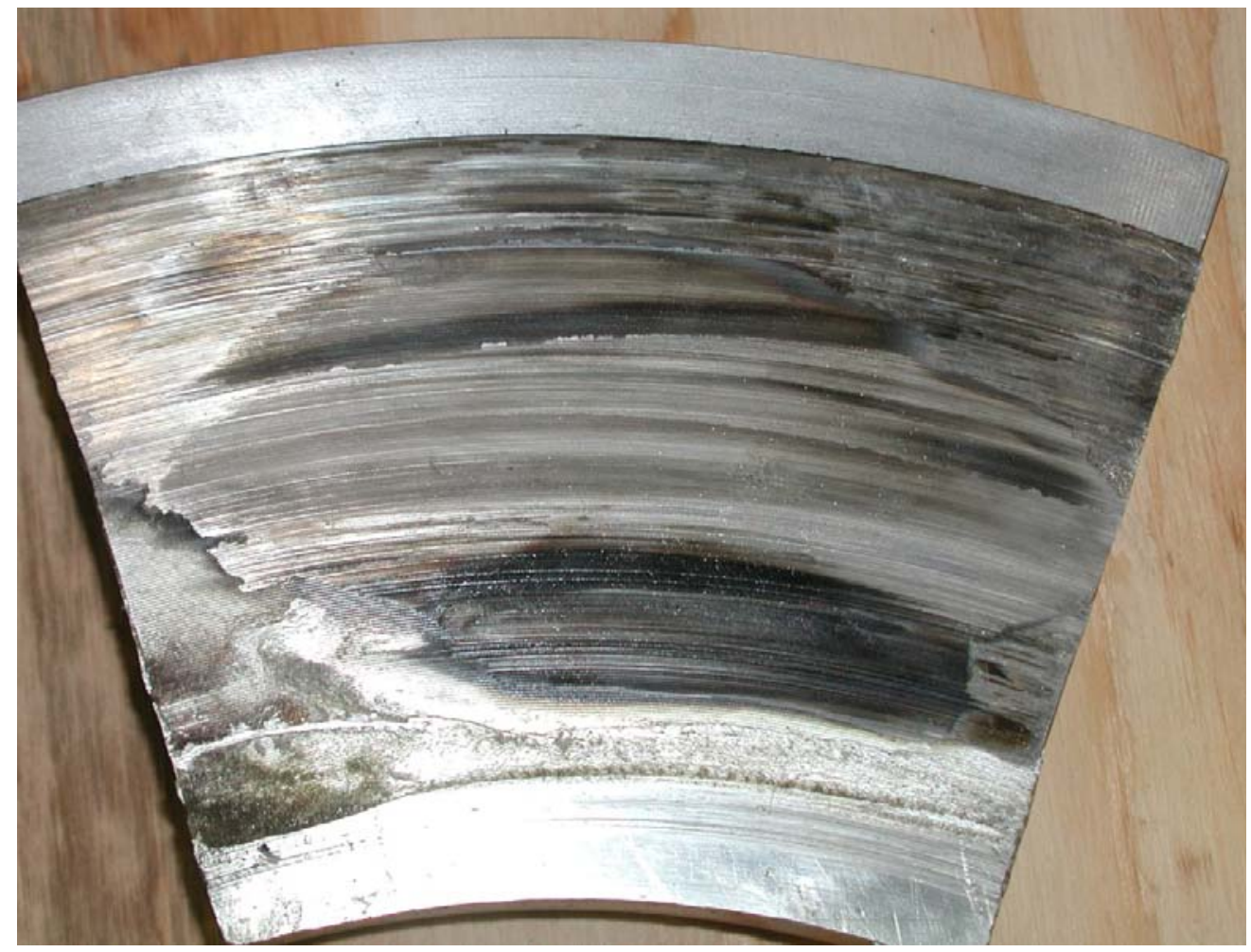

Figure 6. Severe wiping on a thrust shoe (circumferential scratching, narrow lines, also visible). 
- Limited wiping often maintains a viable surface for the continuing operation of the hydrodynamic film. More severe wiping may result in a loss of material which increases the bearing clearance.

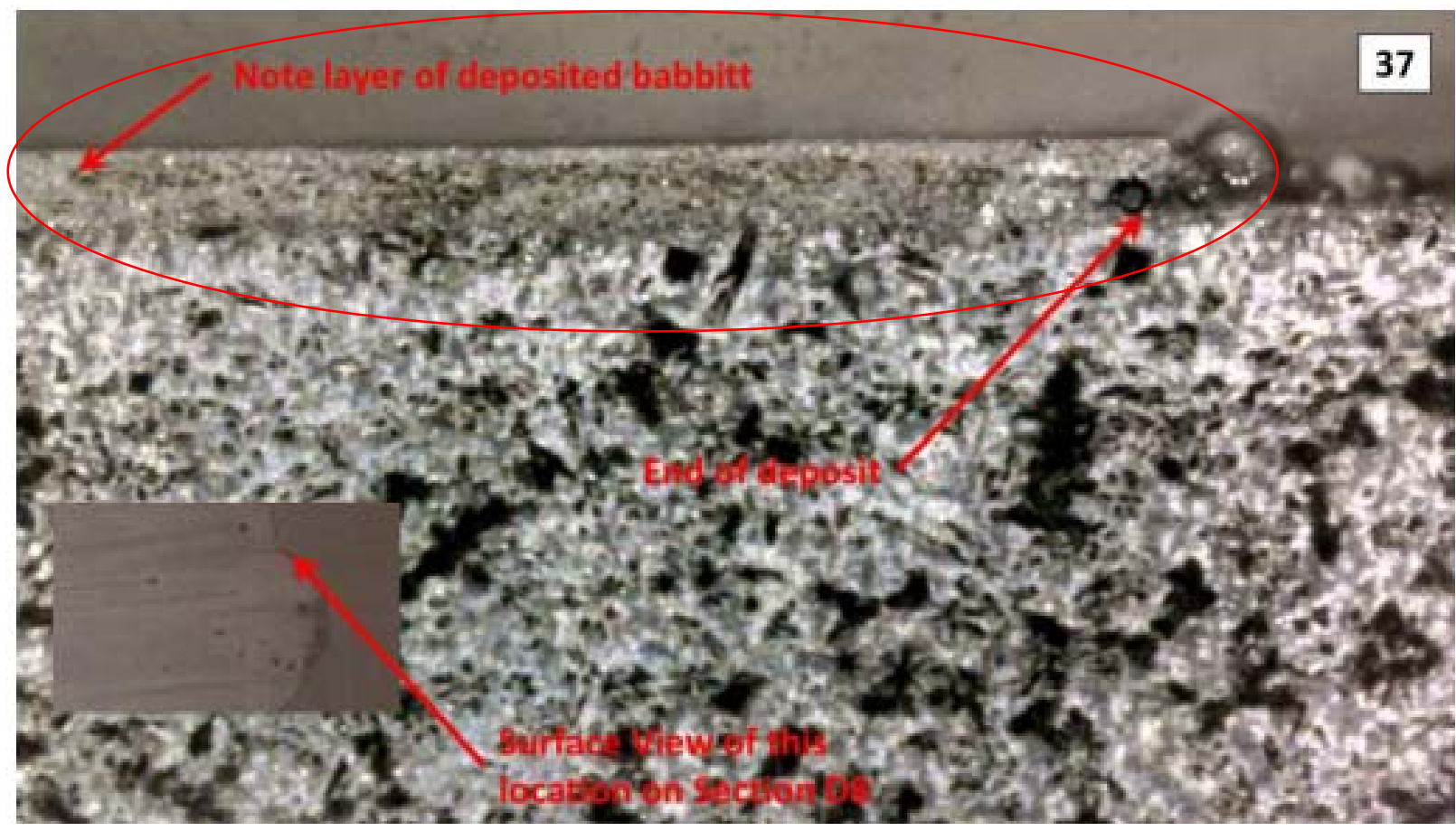

Figure 7. Cross-section appearance of a wiped region on the loaded half of a small cylindrical bearing at $245 \times$ magnification.

The immediate impact of displacement on the hydrodynamic film can be negligible due to the reformation of the working surface on the babbitt (Figure 7). Where significant displacement occurs, the effect would be similar to wear (above). Another concern with displacement is the obstruction of oil flow features, such as grooves, side-wells, slots or ports, which compromises the operation of the hydrodynamic film due to the loss of oil supply (Figure 8).

Surface changes can arise on the babbitt which impact the local operation of the hydrodynamic film:

- Tin Oxide-Tin oxide is a hard material that can form on a babbitt surface in the presence of chlorides, generally from salt water contamination of the lubricant. This formation in a bearing generates hard regions on the babbitt surface which may build in thickness up to $100 \mu \mathrm{m}$ $\left(0.004^{\prime \prime}\right)$. On thrust bearings, this can disrupt the hydrodynamic film. Operation of either radial or thrust bearings with tin oxide build up can release hard particles in to the lubricant which cause abrasive damage.

- Varnish-Degraded lubricant, due to either excessive service time or heat, can form polar molecules which bond with the babbitt surface, typically in the hotter regions of the hydrodynamic film. In most cases this build up, which intrudes into the hydrodynamic film, is insignificant in thickness (see right side of Figure 4). With heavy varnish formation, the varnish layer may continue to build in thickness or to expand in area (see right side of Figure 5). However, the combination of intrusion into the hydrodynamic film and poor heat transfer from the film through the varnish may disrupt the operation of heavily loaded thrust bearings [21]. 


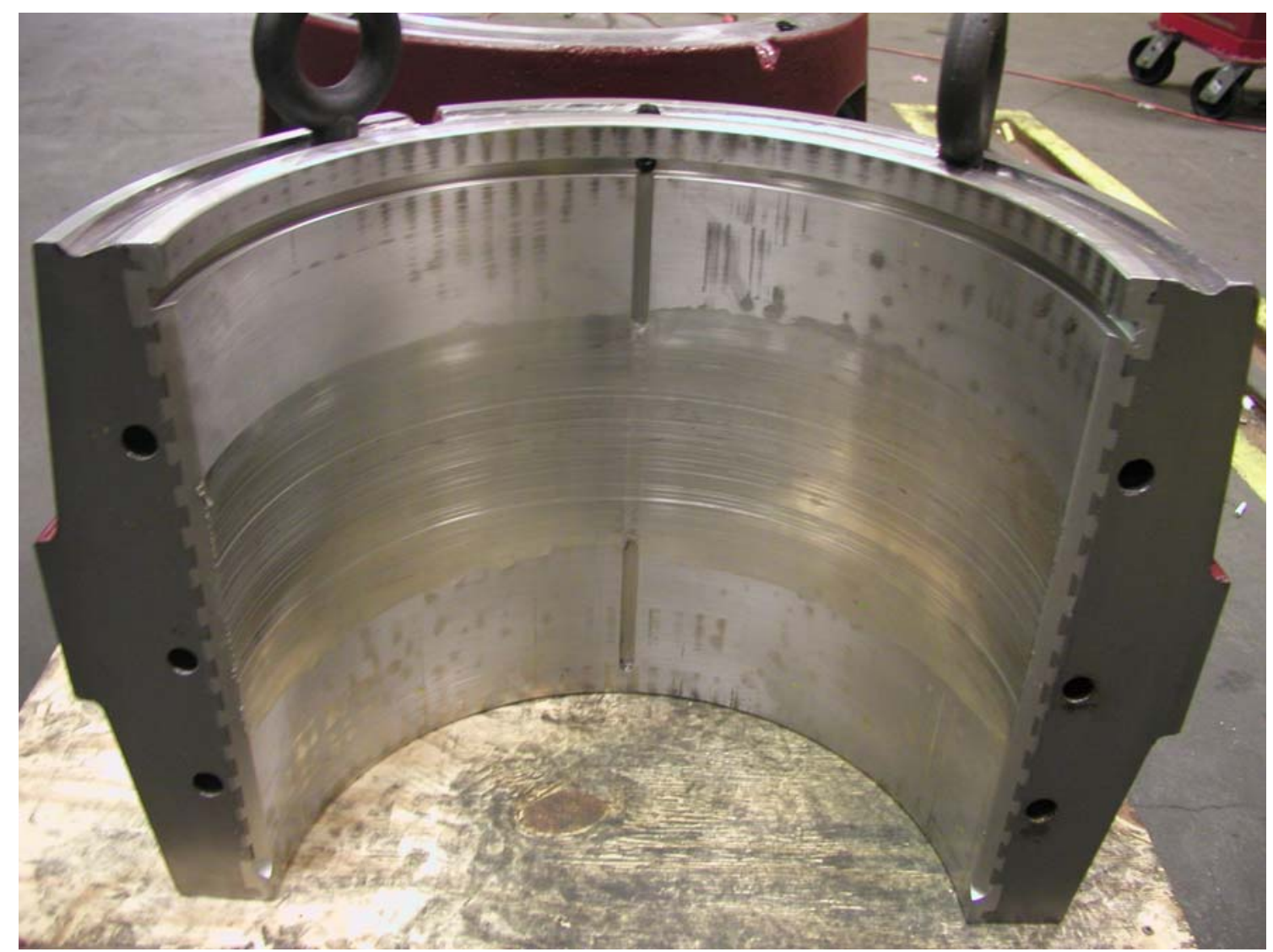

Figure 8. Wiping has covered the axial oil distribution groove on this vertical guide bearing blocking oil flow to the wiped region.

Structure degradation affects mechanical contacts, other than the babbitt surface, such as pivots and fits, between the bearing and its supporting stationary structure. Different bearing designs and different applications have different critical fits.

- Thrust bearing fits provide supper for axial loads and prevent radial motion by means of a fit diameter and/or pins.

- Radial bearing fits provide support for radial loads and define an axial location for the bearing within the machine. Inadequate fits may allow machine vibrations due to looseness. Overly tight fits may distort a thin-wall bearing, with the consequence of reductions in operating film thickness and hot operation or wiping.

- All bearing types have some form of anti-rotation pin typically with a tight fit on the bearing and a loose fit in the surrounding support structure. For multi-lobed radial bearings, a distorted or incorrect pin may place the bearing in an incorrect orientation for the load. For a few bearing designs, a distorted or incorrect pin may allow inadequate alignment of oil supply holes.

- Tilting shoe thrust and tilting pad radial bearings have a mechanical contact between each shoe (or pad) and it's supporting structure. These pivots provide freedom for tilting of the shoe (pad) and define the clearance for that shoe (pad). Degradation of the pivot contacts in radial tilt pads by fretting or galling may impede this tilting leading to changes in machine dynamics, as well as releasing hard contaminants into the lubricant (Figure 9). Degradation of pivot contacts may also increase the operating clearance of the bearing and degrade its load capacity. 
- Tilting shoe thrust bearings may have an additional equalizing arrangement involving a number of additional contact points which collectively define the axial position of individual pads. Degradation of the equalizing arrangement (mild example show in Figure 10) can allow overload of some of the thrust shoes leading to reduced load capacity for the overall thrust bearing.

- Tilting shoe thrust and tilting pad radial bearings may use shims under the pivots or under the bearing carrier for position adjustment of the rotor. Poor contact with the shims may allow fretting wear to release hard particles into the lubricant (severe example shown in Figure 11).

- Radial bearings are generally split to enable assembly. The joint faces of the halves must come together with a tight fit in order to maintain the design clearance profile, to prevent vibrations due to looseness, and to prevent oil leakage. If distorted, the dowel pins which hold the joint faces in proper alignment, will lead to distortion of the clearance profile. Improper distortion or alignment may lead to reduced oil circulation in the hydrodynamic film, hot operation of the bearing and reduced load capacity.

- Distortion of the structure supporting the bearing, whether thermal distortion or mechanical distortion (e.g., from condenser vacuum) can lead to misalignment of the journal (thrust collar) with respect to the babbitt surface of the bearing. This misalignment overloads one region of the hydrodynamic film with the potential for heavy polishing, wear or cracking. In radial bearings this may appear as edge loading. In segmented thrust bearings, this may result in heavy wear on a few shoes, unless an equalizing arrangement is present.

- A proper radial bearing installation attempts to align the journal to its bearing with uniform axial clearance. A proper thrust bearing installation attempts to align the thrust collar to its bearing with uniform circumferential clearance. Errors in assembly or changes between cold setup and hot operation can lead to misalignment (see Figure 12). This misalignment overloads one region of the hydrodynamic film with the potential for heavy polishing, wear or cracking. Changes in machine vibration also result from misalignment.

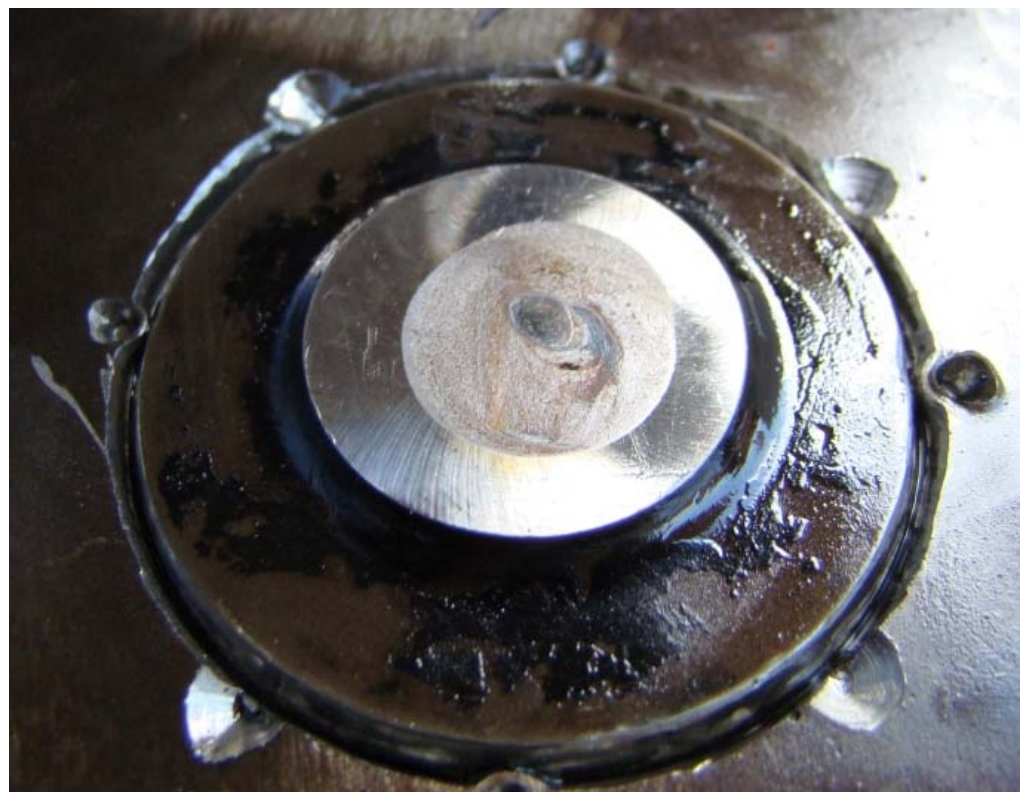

Figure 9. Worn thrust shoe pivot contact showing roughened area (fretting) and material transfer (galling). 


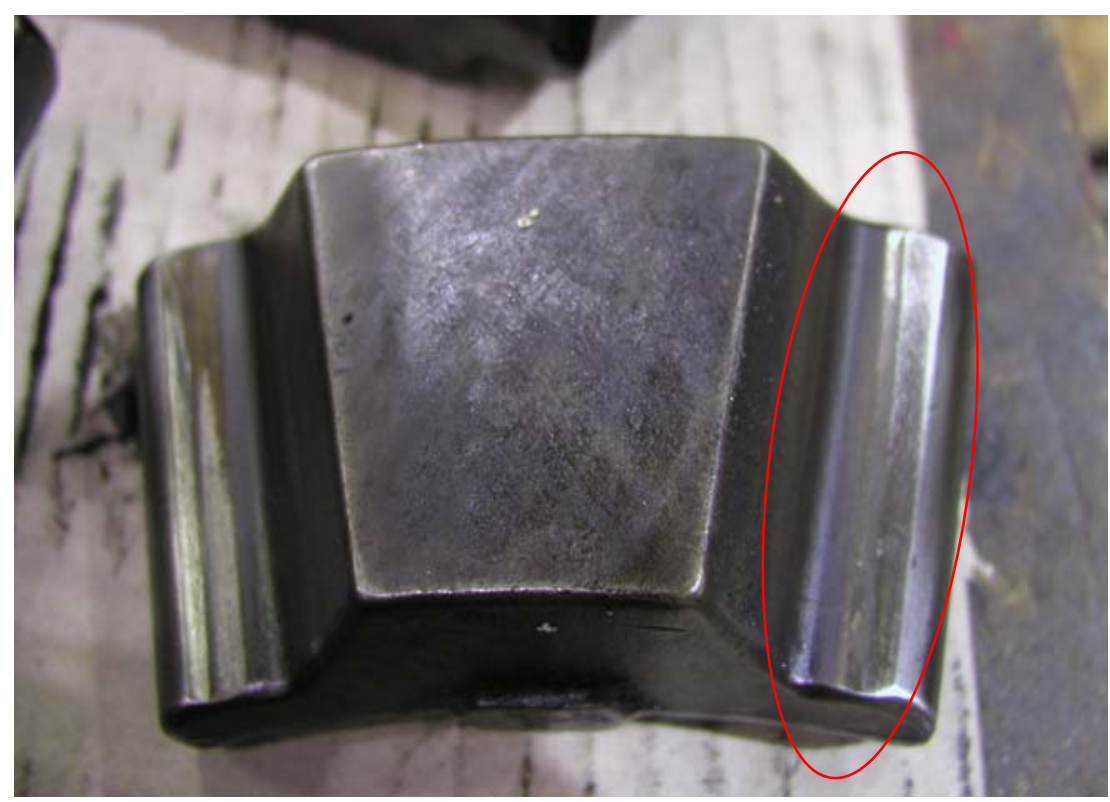

Figure 10. Lower equalizing link from equalized thrust bearing showing mild wear along the contacts.

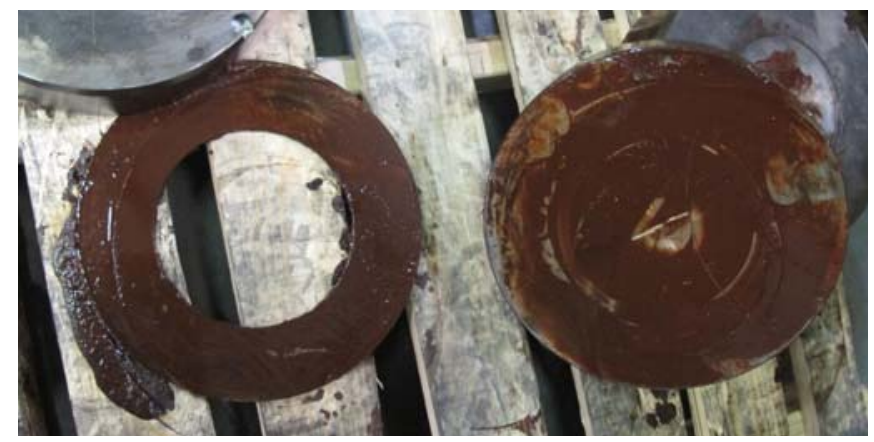

Figure 11. Brown (oily) fretting debris generated between shim (left) and pivot support (right).

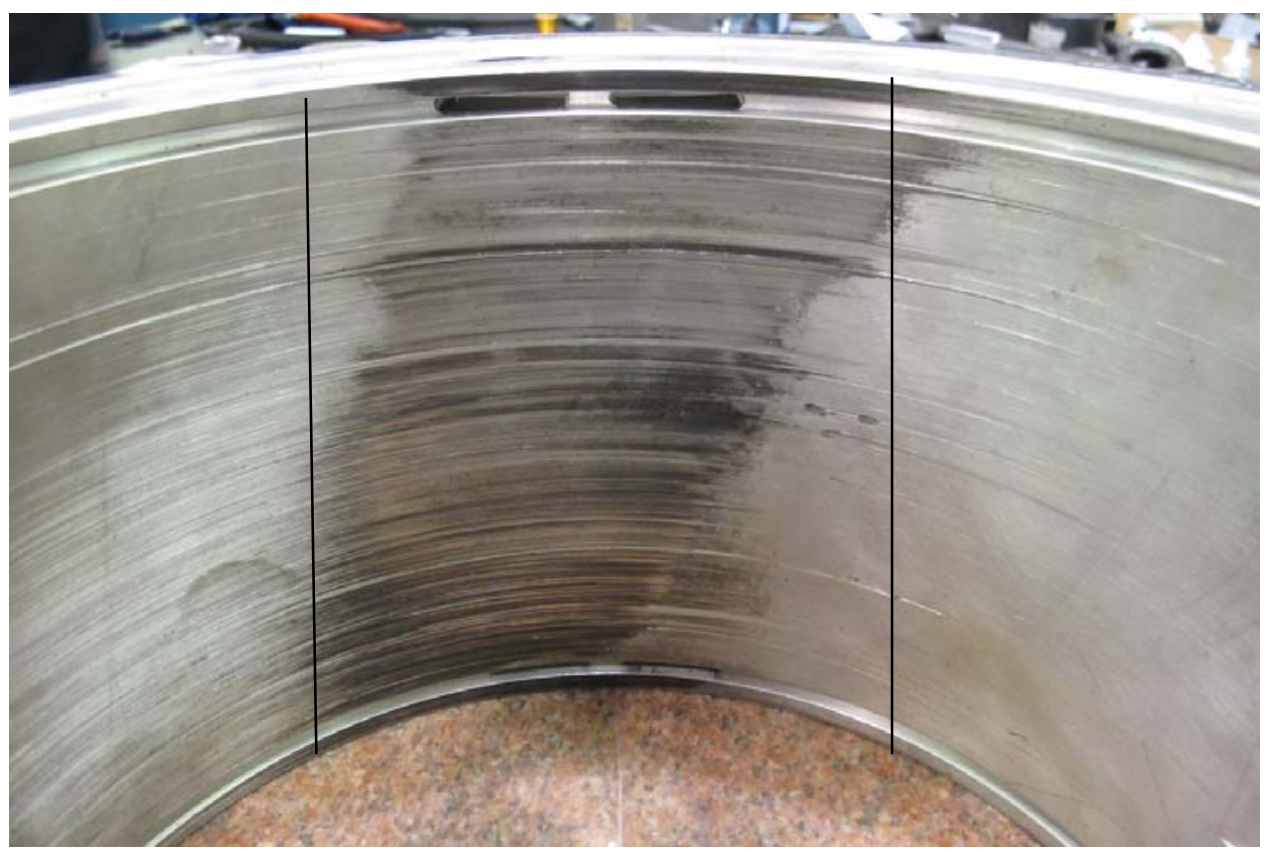

Figure 12. Mild polishing showing left to right misalignment of journal in the bottom half of a large cylindrical bearing. 
Degradation of these different fits may have an impact on the operation of the hydrodynamic film. Wear or deformation of mechanical pivots, whether under a shoe (or pad) or in an equalizing system, will lower the load capacity due to an increase in clearance. For radial bearings, the machine dynamics will be altered by the change in clearance or by a loss of tilt at a pivot. For segmented thrust bearings, an equalizing system may become ineffective due to contact degradation with a reduction of the load capacity of the bearing.

Degradation can also be significant where it is observed on the rotating component, whether the radial bearing journal or the thrust collar.

- Scratches on a rotating component have a similar effect on the hydrodynamic film as would a scratches on the babbitted surface. A rotating deep scratch on a journal (Figure 13) or thrust collar leads to the same load degradation as a corresponding stationary deep scratch on a babbitt surface.

- Journal taper and ellipticity will both degrade the load capacity of the radial bearing by introduction of an axial variation of film thickness.

- Collar wobble will degrade the load capacity of a thrust bearing by introducing a rotating overload of the shoes.

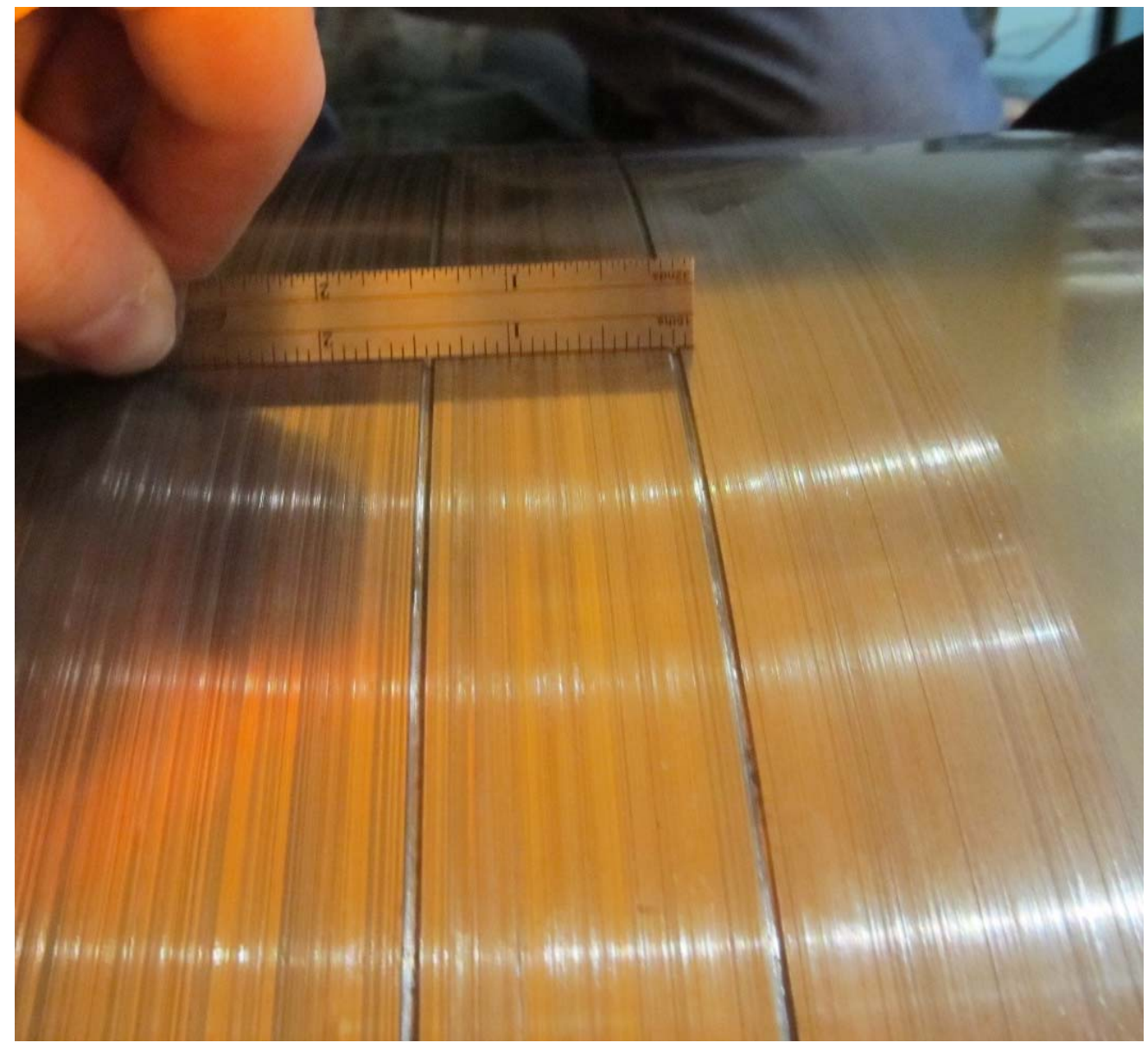

Figure 13. Heavily scored (full $360^{\circ}$ score) bearing journal on large turbine.

An accurate visual evaluation of a used or damaged bearing requires a review of the relevant damage points for that bearing design and an understanding of the dimensions relevant quantifying the impact of that damage on the load capacity or operation of the hydrodynamic film. 
A summary of the potential impact of the different damage observations on the subsequent operation of the bearing hydrodynamic film is presented in Table 1. Not all of the observations discussed will necessarily compromise the subsequent operation of the hydrodynamic film, but may impact the machine operation.

Table 1. Summary of impact of damage mechanisms on operating hydrodynamic film.

\begin{tabular}{ccc}
\hline Appearance & Form & Potential Impact on Operating Film \\
\hline Loss of material & Scratch & Potentially significant loss of load capacity \\
& Bulk loss & Loss of load capacity related to loss of load bearing area \\
Region of cracking & Lears of load capacity related to loss of load bearing area \\
Displacement & Creep & Loss of load capacity related to wear depth \\
Wurface changes & Wiping & Minimal \\
Tin oxide & Varnish & Minimal \\
Structure & Axial fits & Minimal \\
degradation & Radial fits & Minimal \\
& Anti-rotation pin & Minimal \\
& Pivots (radial) & Reduction of effective stiffness and damping \\
& Pivots (thrust) & Minimal \\
& Equalizing contacts (thrust) & Altering effective stiffness and damping \\
& Joint fact contact (radial) & Loss of load equalization \\
& Distortion of structure & Loss of load equalization \\
& Installation misalignment & Loss of load capacity due to induced misalignment \\
& Scratches & Potentially significant loss of load capacity \\
& Taper and ellipticity & Potentially significant loss of load capacity \\
& Collar wobble (thrust) & Dynamic variation of shoe loads \\
\hline & &
\end{tabular}

In conjunction with visual examination, other off-line measurements can provide insight as to the suitability of a used or damaged bearing:

- Ultrasonic examination of the babbitt surface can determine the integrity of the bond between the babbitt and the supporting material, generally a steel or copper alloy (using, for example, [22]). Lack of integrity in a load bearing region can lead to surface displacement or cracking which would then impact the operation of the hydrodynamic film.

- Dye penetrant examination of the babbitt surface (using, for example [23]) can reveal porosity or cracking which may be too fine for visual observation. Depending on the total area, porosity would be a form of loss of material. A severe region of porosity, visual without applying dye penetrant can be seen in Figure 14. A single crack or narrow crack network would have the impact of a scratch. A broader crack network would have the impact of a loss of material.

- Dye penetrant examination of the interface between the babbitt and the supporting material, an examination prone to false positives, can be used to indicate when an additional ultrasonic examination with a smaller diameter probe might be required. 
- Tin based babbitt should have a higher mechanical strength than the stresses induced by the applied loads. Certain contaminants in the babbitt, such as lead, can uniformly lower this strength. Some tin babbitt formulations have an inherently higher resistance to creep or a higher compressive strength than others. Local deformation of the babbitt due to an inadequate formulation is generally negligible for industrial bearing designs.

- Measuring the composition of babbitt can be difficult due to the need to obtain a representative sample, as babbitt is a coarse mixture of compounds. Babbitt composition will change from the original material supplied to the composition of the material after casting and again to the material after extended service.

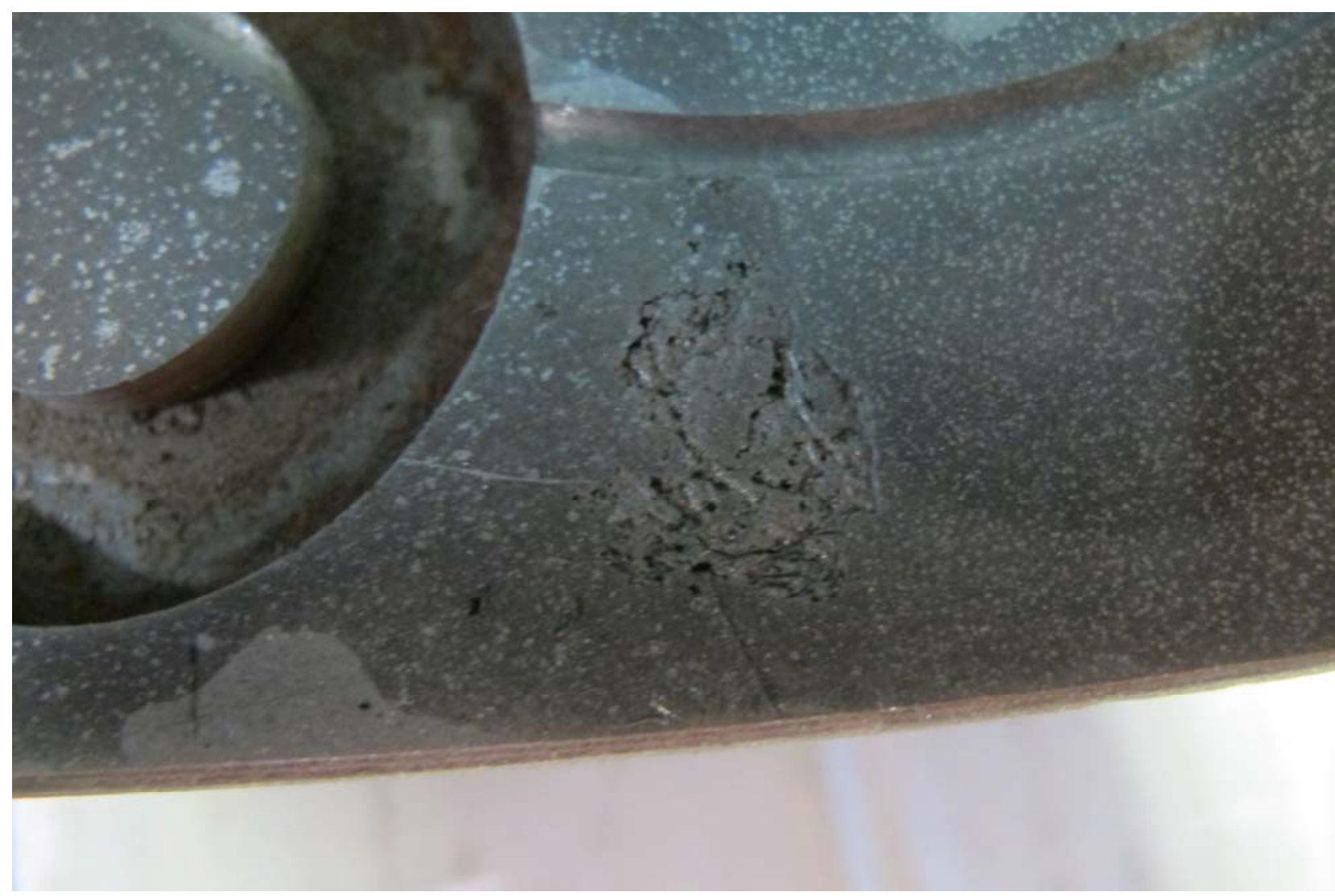

Figure 14. Large region of visual surface porosity with multiple linear indications from static casting observed on a test sample.

\subsection{Degradation Related to Machine Operation}

The observations previously discussed which impact the hydrodynamic film often are caused by conditions of the machine or the bearing lubricant. Using the three categories of observations (loss of material, displacement and support degradation), additional sub-categories are required to identify the source of the bearing degradation.

In the previous section three sub-categories were listed under "loss of material", namely, scratches, bulk loss, wear. In considering the source of degradation, additional sub-categories are often beneficial.

- Scratches can be attributed to: 
o Lubricant Contamination - most contaminants carried by a lubricant will be harder than the babbitt surface, and in many cases, harder than the journal (thrust collar). Scratches from these contaminants will follow the flow path of the lubricant. Circumferential scratches would be expected from normal operation of a journal or thrust bearing, although a radial component will also be observed on a babbitt scratch in a thrust bearing. Scratches associated with lubricant exiting a hydrostatic lift pocket would generate scratches distributed outward from the pocket, although possibly with a circumferential component if the machine rotor is turning when the scratching occurred.

o Worm Tracks - are generally due to rotating magnetism. A magnetic particle in the lubricant may interact with a magnetic field induced by rotor rotation to scratch the babbitt surface. These scratches are characterized by sudden changes in scratch orientation, often with a strong non-circumferential direction (see Figure 15).

o Handling Scratches-non-circumferential scratches, for example axial scratches on journal bearings, often arise during handling of the babbitted components, either during assembly or disassembly, or during shipping of the bearing. Scratches during handling may be quite deep as the damaging components may be quite large.

o Cracking - cracks limited in length or number can arise from local overheating of the babbitt or initial cracking around a region of poor babbitt bond.

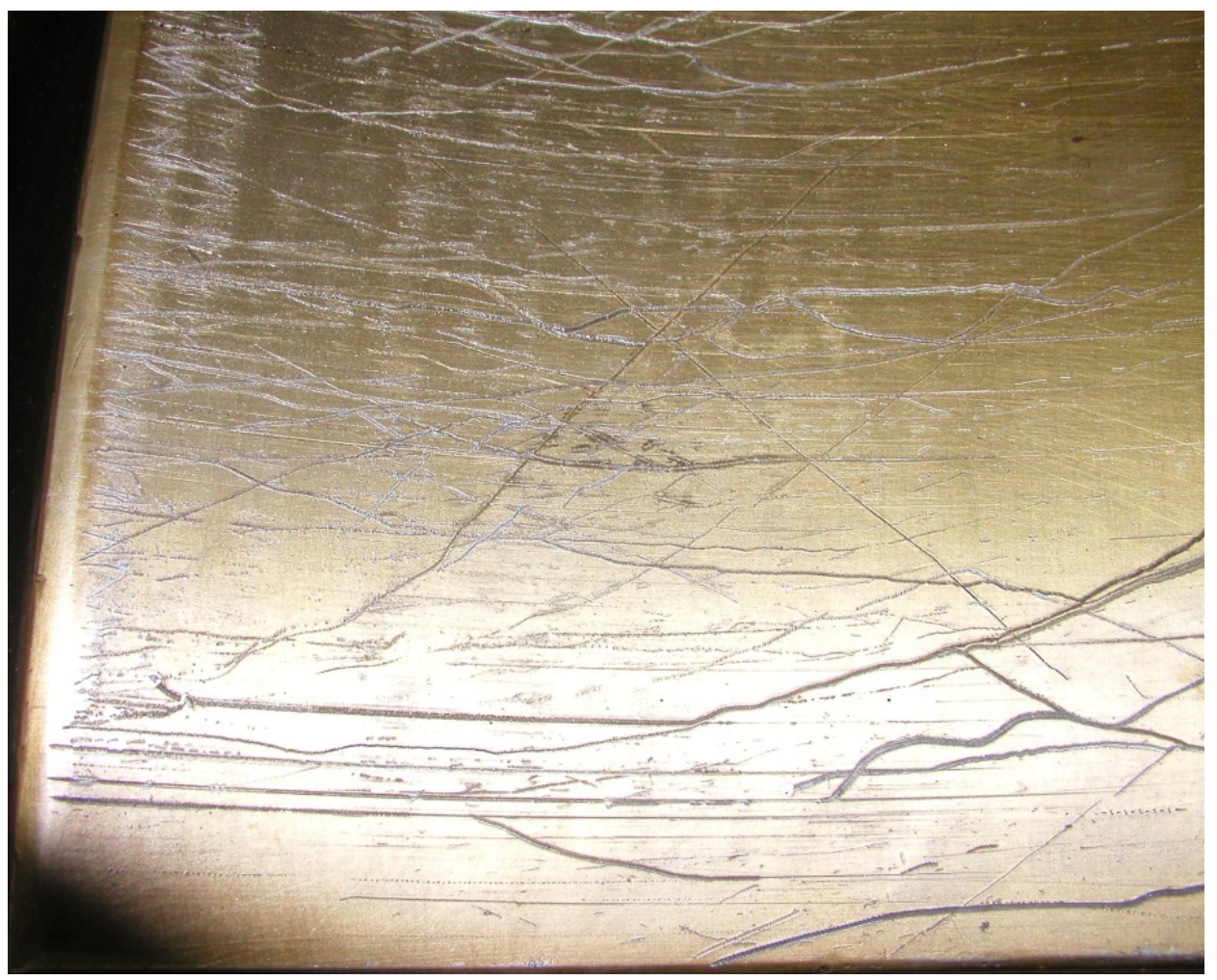

Figure 15. Region with multiple worm tracks observed near the corner of the leading edge of a large radial tilt pad.

- Bulk loss of material can be attributed to several mechanisms based on the shape of the babbitt deficit and its character. Ductile failure of babbitt will leave an angular fracture surface along grain boundaries, unless subsequent bearing operation rounds the fracture surface. 
o Large Deficit_ "pot holes" in the babbitt can arise from several causes.

- Severe electrical damage, such as due to improper grounding of a welder, leads to a wide deep area of loss. The edges of the babbitt loss will generally be smooth rather than angular.

- A large section of babbitt may become separated due to an underlying broken bond, where inadequate bond is the underlying cause. The fracture surfaces on the remaining intact babbitt will initially be along grain boundaries. Over subsequent operation, some rounding of the fracture surfaces will occur.

- A region of fatigue cracking may eventually lead to a large loss of material as the network of cracking propagates and pieces of babbitt are released to be carried out of the bearing by the lubricant. Such fatigue damage is encountered in radial bearings where the dynamic loads exceed the static loads.

o Pit(s) - Individual pits, or craters, can arise from several causes. The pit formation involves initially displacing material around the rim which is likely to be removed, possibly leaving a thin polished ring, during subsequent bearing operation.

- Electrolysis generates pits on both the babbitt surface and on the journal (thrust collar) during a static electricity discharge across the lubricated clearance space, either near a point of minimum clearance or in a region of incomplete oil film (diverging clearance space). Multiple small pits are generally observed, where subsequent discharges will strike around the initial pit, but not coincident [24].

- Porosity arises during the cooling of the babbitt after casting and is more common after static casting, as is required for thrust bearings and some journal bearing designs. With good casting practice, the porosity should be limited to a few small pits, without linearity (see [22]).

o Erosion-Areas of very high lubricant velocity on the babbitt surface may lead to erosion, such as at the corners of a machined step or at the end of a section of wiped babbitt. Some difficulty may arise in discriminating between erosion, which is driven by flow velocity, and cavitation, where the flow velocity leads to a change from vapor to gas of the lubricant, or some fraction of the lubricant. Individual "canyons" tend to become deep rather than wide.

o Moderate-Chromium Steels - When used as a journal (thrust collar) surface, medium-chromium steels show a tendency towards somewhat random events of deep, progressive scratching of the babbitt and journal (thrust collar). Termed "wire wooling", where the scratching results in strands of journal which form a small clump of wire-sized shavings, the damage progresses from circumferential scratching to significant localized (in area) damage [25].

- Wear-A progressive loss of material over large segment of the loaded area of the bearing. Most bearings after operation show a region of polishing, which often represents only insignificant wear. More significant wear can develop under a number of circumstances.

o Ditching-Developing during extended low-speed (turning gear) operation, wear may be concentrated near the "bottom" of the bearing, not necessarily in the absence of a hydrostatic lift (jacking) system, as discussed in [26]. 
o Tapered Land Designs-Used for thrust bearings, and occasionally in radial bearings, tapered lands terminate in a land region. Due to operation, wear may occur on this land region, leading to an increase in thickness of the land region and an increase of clearance. Tapered land thrust bearings are often designed so that the load capacity of the bearing increases with the initial increase in land thickness.

o Long Term Wear-Where a bearing inspection reveals only minimal damage or damage which can be removed, a scraping operation will restore a smooth surface to the babbitt. Over time, or with more severe damage, this scraping can increase the clearance in the bearing, leading to changes, possibly undesirable, in machine dynamics (vibrations) and operating temperatures.

- Surface Displacement-A surface of layer can be disturbed due to a combination of thermal and mechanical effects.

o Creep-Creep arises where the combination of local operating temperature and local hydrodynamic pressure exceeds the local mechanical strength of the babbitt. The surface of the babbitt will slowly displace from regions of high material stress towards low stress. Creep is often associated with displacement due to higher-than-expected temperatures over time. A creep calculation for large thrust bearings is described in [27].

o Wiping-Wiping involves rapid heating of a region of the babbitt surface due to contact between the journal (thrust collar) and the babbitt surface. This contact represents a local breakdown of the hydrodynamic film and results in a sharp increase in friction from the contact. The friction energy may be dissipated by displacement of some of the babbitt from regions away from the contact. While often self-correcting, wiping may become progressively more severe:

- Where the friction heating is due to a loss of the hydrodynamic film and operation under boundary lubrication conditions.

- If the friction heating of a journal causes a thermal expansion of the journal which maintains the contact. Where this occurs, the wiping may extend nearly 360 degrees around the bearing and be termed a "seizure" $([28,29])$. Seizure is more common on lightly loaded vertical bearings, which have a smaller design clearance than a horizontal bearing of comparable diameter.

- If the wiping impedes the oil distribution slot or groove and reduces the oil flow to the hydrodynamic film.

o Hydrogen Blisters-The steel shell in a new bearing may contain hydrogen depending on the steel making process details. Atomic hydrogen in the steel can migrate toward a new babbitt bond line and form molecular hydrogen with sufficient increase in volume to break the bond. This results in a local radial displacement of the Babbitt (Figure 16), typically in areas of thinner babbitt as found in oil grooves or overshot pockets [30]. 


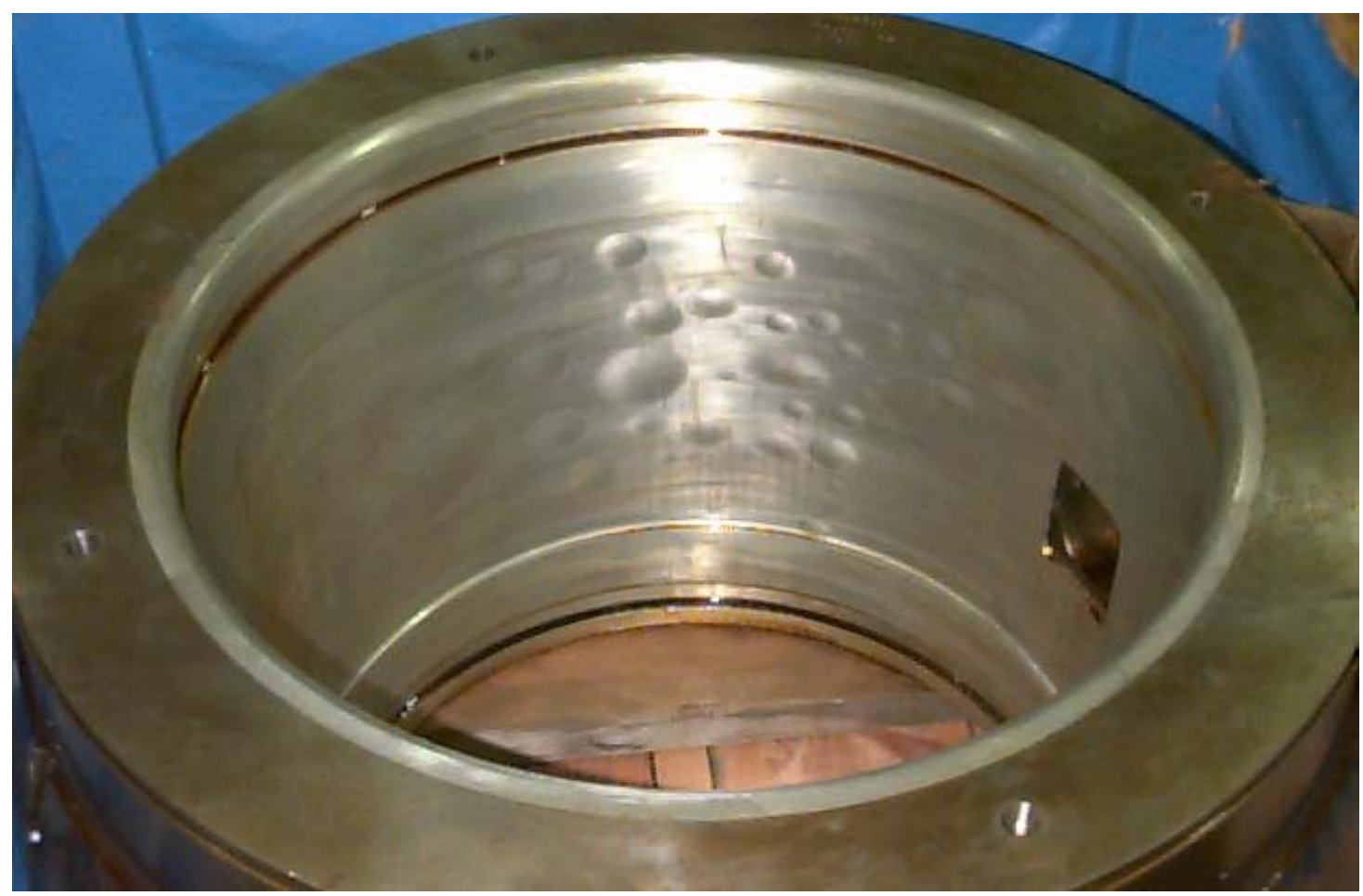

Figure 16. Hydrogen blisters (protruding towards into the bore) in the region of thinner babbitt in the overshot groove in the upper half of a large cylindrical generator bearing.

- Surface Changes (see also [31]):

o Surface Corrosion-After time, aging stagnant oil and some acids may lead to corrosion of the surface of a tin-based babbitt. The resulting attach will leave small angular deficits in the babbitt, as the corrosion selectively attacks the tin, copper or antimony. Closer inspection is required to discriminate this appearance from pitting, which would be rounded.

o Polishing - As noted in the discussion of wear, most bearings show a region of polishing due to normal service. This polishing can reveal additional details about the machine or bearing.

- The use of dovetails or mechanical anchors in the bearing shell creates thick and thin regions under the babbitt surface. Due to the greater thermal expansion of the thicker regions, the polishing will preferentially occur over the thicker regions revealing a pattern of dovetails and anchors. This preferential polishing is more pronounced in the hotter regions of the bearing.

- The polishing region may show a bias or wider extent on one axial side of a journal bearing than on the other. This generally occurs due to a local misalignment of the journal relative to the bearing occurring during operation. The periods of misalignment may be continuous or during transients of the bearing shell.

- Anisotropy-The thermal expansion of babbitt varies with orientation of the grain boundaries. During operation at hotter temperatures, which could be consistent with the design operating temperatures, the thermal expansion could lead to distortion along the grain boundaries [32]. With long term operation, this anisotropy of the thermal expansion could result in a slight rippling of the babbitt surface. No impact on the hydrodynamic 
film is anticipated as the rippling is generally minimized by in-service polishing of the high points of the ripples.

o Tin Oxide-Tin oxide is a hard substance that may form on a babbitt surface in the presence of chlorides, generally from salt water contamination of the lubricant. This formation generates hard regions on the babbitt surface which may build in thickness up to $100 \mu \mathrm{m}$ $(0.004 ")$. On thrust bearings, this can disrupt the hydrodynamic film as well as releasing hard particles to cause abrasive damage.

o Varnish-Degraded lubricant, due to either excessive service time or heat, can form polar molecules which bond with the babbitt surface, typically in the hotter regions of the hydrodynamic film [33]. In most cases this build up is insignificant in thickness relative to the operating thickness of the hydrodynamic film. With heavy varnish formation, the varnish layer may continue to build in thickness or to expand in area, representing a continuing breakdown of the lubricant.

o Speckling - Some harder babbitt alloys contain antimony in excess of the saturation level for antimony in tin (about 7\%). This results in the formation of additional antimony-tin cuboids during the casting process. After long-term operation of a bearing with this material at hotter temperatures, although consistent with the design operating temperatures, additional antimony-tin cuboids may be observed on the babbitt surface. The shiny aspects of these cuboids will give the surface a more speckled appearance. No impact on the hydrodynamic film is anticipated although the harder cuboids will alter any wear progress of the surface. Speckling can be observed around the porosity shown in Figure 14.

\section{- Structural Support Changes}

o Fretting-Fits of bearings, joint faces, thrust collars, thrust blocks and similar components are subject to fretting over long periods of operation where relative motion can occur [34]. Fretting results in removal of material and a reduction in the quality of the fit. This may impact the operation of the hydrodynamic film where fretting wear affects the bearing clearance and may lead to increases in machine vibration where fretting wear leads to looseness. Further, fretting tends to be a steadily accelerating process as the initial fretting develops looseness which allows for an increased severity of the fretting.

o Cracking-Hardened steels used in mechanical pivots for tilting pads and shoes can crack in service, especially where impact loads occur. Where the crack disrupts of the tilting of the shoe or pad, changes in machine vibration, often an increase in amplitude, may be observed during machine operation.

o Misalignment-A proper radial bearing installation attempts to align the journal to its bearing with uniform axial clearance. A proper thrust bearing installation attempts to align the thrust collar to its bearing with uniform circumferential clearance. Errors in assembly or changes between cold setup and hot operation can lead to misalignment (see Figure 12). This misalignment overloads one region of the hydrodynamic film with the potential for heavy polishing, wear or cracking. Changes in machine vibration also result from misalignment. 
A summary of the potential impact of the different damage observations on the subsequent operation of the bearing hydrodynamic film is presented in Table 2. Not all of the observations discussed will necessarily compromise the subsequent operation of the hydrodynamic film, but may impact the machine operation.

Table 2. Sources of damage to bearing from lubricant, maintenance, manufacture and machine operation.

\begin{tabular}{|c|c|c|}
\hline Appearance & Form & External Causes of Damage \\
\hline \multirow[t]{5}{*}{ Loss of material } & Scratch & Lubricant condition, journal condition, rotating magnetism, handling \\
\hline & Bulk loss & $\begin{array}{c}\text { Poor babbitt bond, distortion during handling, electrical damage, } \\
\text { fatigue progression, erosion, wire-wooling }\end{array}$ \\
\hline & Pits & Electrolysis, porosity \\
\hline & Region of cracking & Dynamic loads in excess of static loads, structural degradation \\
\hline & Wear & Lubricant condition, operation under boundary lubrication \\
\hline \multirow[t]{3}{*}{ Displacement } & Creep & High temperature operation \\
\hline & Wiping & Loss of hydrodynamic film, seizure, interruption of lubricant flow \\
\hline & Blisters & Hydrogen in new steel \\
\hline \multirow[t]{2}{*}{ Surface changes } & Tin oxide & Exposure to saline water \\
\hline & Varnish & Lubricant breakdown \\
\hline \multirow[t]{9}{*}{$\begin{array}{c}\text { Structure } \\
\text { degradation }\end{array}$} & Axial fits & Error in manufacturing, fretting, repeated disassembly \\
\hline & Radial fits & Error in manufacturing, fretting, repeated disassembly \\
\hline & Anti-rotation pin & Seizure during operation, repeated disassembly \\
\hline & Pivots (radial) & Fretting, overload, machine vibration \\
\hline & Pivots (thrust) & Overload, collar wobble \\
\hline & $\begin{array}{l}\text { Equalizing contacts } \\
\text { (thrust) }\end{array}$ & Overload, collar wobble \\
\hline & Joint fact contact (radial) & Fretting, repeated disassembly \\
\hline & Distortion of structure & Poor fits, excessive pinch \\
\hline & Installation misalignment & Thermal or mechanical machine changes during operation \\
\hline \multirow[t]{3}{*}{$\begin{array}{c}\text { Journal } \\
\text { degradation }\end{array}$} & Scratches & Lubricant condition \\
\hline & Taper and ellipticity & Long term wear, manufacturing error \\
\hline & Collar wobble (thrust) & Assembly error, wear on running surface \\
\hline
\end{tabular}

\section{Conclusions}

Visual observations of damage to the whitemetal (babbitt) surface of industrial journal and thrust bearings have been categorized and discussed with the goal of supporting the answer to the maintenance question:

- Is the bearing suitable for continuing operation as-is, after only a simple cleaning?

A reduced set of categories of off-line visual observations is suggested:

- Loss of babbitt (whitemetal),

- Babbitt (whitemetal) displacement, 
- Surface changes to the babbitt (whitemetal), and

- Structural changes to the bearing and supports.

The determination as to the suitability of a used bearing for re-use builds on these observations, with additional input from a determination of the design load margin, on-line measurements of bearing temperature and machine vibration, and additional off-line measurements using ultrasonic and dye penetrant techniques.

Visual observations are also discussed in this paper with respect to the role of the bearing in the overall machine, addressing the maintenance question:

- What do the visual observations from the babbitt surface reveal about the interaction of the bearing with the machine, lubricant and operating conditions?

The same categories of off-line visual observation can provide insight in the machine and lubricant conditions which may affect the reliability of the machine.

\section{Author Contributions}

Lyle A. Branagan is the sole author of this work.

\section{Conflicts of Interest}

The authors declare no conflict of interest.

\section{References}

1. Plain Bearings_Lead and Tin Casting Alloys for Multilayer Plain Bearings; ISO Standard 4381:1991; International Standards Organization: Geneva, Switzerland, 1991.

2. Wilson, R.W.; Shone, E.B. The diagnosis of plain bearing failures. In Industrial Tribology: The Practical Aspects of Friction, Lubrication and Wear; Jones, M.H., Scott, D., Eds.; Tribology Series 8; Elsevier: Amsterdam, The Netherlands, 1983; pp. 97-101.

3. Gleitlager: Begriffe, Merkmale und Ursachen von Veränderungen und Schäden; DIN Standard \#31661; German Institute for Standardization: Berlin, Germany, 1983.

4. Koring, R.M. Rules for Handling Whitemetal-Bearing Damages; ECKA Granulate Essen GmbH: Fürth, Germany, 2004.

5. Koring, R.M. Changes in Plain Bearing Technology; Expert Verlag and SAE International: Warrendale, PA, USA, 2012.

6. Manual of Bearing Failures and Repair in Power Plant Rotating Equipment; \#GS-7352; Electric Power Research Institute: Palo Alto, CA, USA, 1991.

7. Manual of Bearing Failures and Repair in Power Plant Rotating Equipment; \#1021780; Electric Power Research Institute: Palo Alto, CA, USA, 2011.

8. Glacier Metal Co., Ltd. Bearing Damage; CG284/2/85; Glacier Metal Co., Ltd.: Northwood Hills, UK, 1985.

9. Pioneer Motor Bearing Company. Bearing Damage_Flip Chart, 3rd ed.; Pioneer Motor Bearing Company: Kings Mountain, NC, USA, 2007. 
10. Federal-Mogul RPB Ltd. Bearing Damage; Federal-Mogul RPB Ltd.: Northwood Hills, UK, 2000.

11. Kingsbury, Inc. A General Guide to the Principles, Operation and Troubleshooting of Hydrodynamic Bearings; Publication HB: Philadelphia, PA, USA, 1997.

12. Bravo, A.E.; Duran, H.A.; Jacobo, V.H.; Ortiz, A.; Schouwenaars, R. Towards New Formulations for Journal Bearing Alloys. Wear 2013, 302, 1528-1535.

13. Rolf, K. Improved Bearing Alloy-A Contribution to Environmental Protection. In Proceedings of the Thirty-Second Turbomachinery Symposium, College Station, TX, USA, 8-11 September 2003; pp. 85-89.

14. Branagan, L.A. Categories of Impact of Bearing Damage on Hydrodynamic Film Operation. In Proceedings of the 12th EDF/Pprime Workshop, Futuroscope, France, 17-18 September 2013.

15. Branagan, L.A. Toward a Quantitative Analysis of Journal and Bearing Scratches. In Proceedings of the 5th EDF \& LMS Poitiers Workshop: Bearing Behavior under Unusual Operating Conditions, Futuroscope, France, 5 October 2006.

16. Dobrica, M.B.; Fillon, M. Performance Degradation in Scratched Journal Bearings. Tribol. Int. 2012, 51, 1-10.

17. Shintaro, W.; Kunio, S.; Sadao, A.; Masatoshi, F. Evaluation for Wear Lift of Journal Bearing Lubricated by Contaminated Oils. In Proceedings of the JSLE International Tribology Conference, Tokyo, Japan, 8-10 July 1985; pp. 85-90.

18. Begelinger, A.; de Gee, A.W.J. Wear in Lubricated Journal Bearings. J. Tribol. 1978, 100, 104-109.

19. Nikolakopoulos, P.G.; Papadopoulos, C.A. Performance Characteristics of Worn and Misaligned Journal Bearings. In Proceedings of the 5th EDF \& LMS Poitiers Workshop: Bearing Behavior under Unusual Operating Conditions, Futuroscope, France, 5 October 2006; pp. H1-H8.

20. McCabe, R.J.; Morris, E.F. Creep of Tin, Sb-Solution-Strengthened Tin, and SbSn-Precipitate-Strengthened Tin. Metall. Mater. Trans. 2002, 33A, 1531-1539.

21. Kingsbury, Inc. High Thrust Bearing Temperatures Due to Varnish. Available online: http://www.kingsbury.com/High-Thrust-Bearing-Temperatures-Due-to-Varnish.shtml (accessed on 13 November 2013).

22. Plain Bearings-Metallic Multilayer Plain Bearings-Part 1: Non-Destructive Ultrasonic Testing of Bond; ISO Standard 4386-1:1992; International Standards Organization: Geneva, Switzerland, 1992.

23. Plain Bearings-Metallic Multilayer Plain Bearings_Part 3: Non-Destructive Penetrant Testing; ISO Standard 4386-3:1992; International Standards Organization: Geneva, Switzerland, 1992.

24. Bothwell, J.S. Controlling Shaft Voltages. Dated 15 May 2007. Available online: http://www.powermag.com/category/instrumentation-controls/ (accessed on 19 September 2014).

25. Fidler, F. Metallurgical Considerations in Wire Wool Type Wear Bearing Phenomena. Wear 1971, 17, 1-20.

26. Dufrane, K.F.; Kannel, J.W.; McCloskey, T.H. Wear of Steam Turbine Journal Bearings at Low Operating Speeds. J. Lubr. Technol. 1983, 105, 313-317.

27. Ettles, C.M.; Seyler, J.; Bottenshein, M. Calculation of a Safety Margin for Hydro Generator Thrust Bearings. Tribol. Lubr. Technol. 2006, 62, 46-54. 
28. Dufrane, K.F.; Kannel, J.W. Thermally Induced Seizures of Journal Bearings. J. Tribol. 1989, 111, 288-292.

29. Hazlett, T.L.; Khonsari, M.M. Thermoelastic Behaviour of Journal Bearings Undergoing Seizure. Tribol. Int. 1992, 25, 183-187.

30. Baudry, R.A.; Gunther, D.W.; Winer, B.B. Prevention of Babbitt Blisters in Thrust-Bearing Pads. Trans. ASME 1954, 76, 255-260.

31. Biswas, S.; Chander, T.; Gole, D.S. Some Observations on the Surface and Subsurface Features of Failed Babbitt Pads. Tribol. Int. 1984, 17, 99-105.

32. Branagan, L.A.; Cleminson, J.C. Thermal Fatigue of Several Babbitts on Flat Plates: Part I Unloaded Expansion. In Proceedings of the \#IJTC2006-12216, STLE/ASME International Joint Conference, San Antonio, TX, USA, 23-25 October 2006.

33. Day, L. Solving Varnish Problems in Gas Turbine Lubricants. Tribol. Lubr. Technol. 2008, $64,32$.

34. Johnson, K.L.; O'Connor, J.J. Mechanics of Fretting. In Proceedings of the Institution of Mechanical Engineers, 178 Part 3; Institution of Mechanical Engineers: London, UK, 1963/1964; pp. 7-21.

(C) 2015 by the authors; licensee MDPI, Basel, Switzerland. This article is an open access article distributed under the terms and conditions of the Creative Commons Attribution license (http://creativecommons.org/licenses/by/4.0/). 